\title{
O TRABALHO DOCENTE NOS ESPAÇOS HOSPITALARES: UM DESAFIO NA CONTEMPORANEIDADE
}

\author{
Antônio Carlos Sobrinho Filho ${ }^{1}$ \\ Edilson Raniere Gonçalves Pereira ${ }^{2}$ \\ Gerúnia Moraes Santos Carlos ${ }^{3}$
}

RESUMO: O foco de estudo do presente artigo se debruça sobre uma pesquisa de caráter bibliográfico que faz uma análise aprofundada da atuação docente dentro de instituições hospitalares. Um trabalho voltado para atendimento pedagógico a estudantes que se encontram em situação de internação e, por isso, ficam impossibilitados de ir à escola. A produção aborda aspectos do contexto histórico, em que são levantados pontos importantes que formam uma linha do tempo da educação hospitalar no Brasil. Somado a isso, traz também os marcos legais que enquadram a educação hospitalar como uma modalidade pertencente à educação especial, fato que garante ao estudante hospitalizado o pleno direito à educação. Além desses pontos, o artigo propõe sugestões para a prática pedagógica dentro dos espaços hospitalares, diagnosticando situações que permitam uma atuação docente efetiva e uma aprendizagem discente significativa. Ainda, são tratados aspectos da gamificação nesses espaços como forma de construção do conhecimento cognitivo nos estudantes hospitalizados. A produção contou com a contribuição de Machado e Campos (2013), Berdel (2011), Diesel, Baldez e Martins (2017), Lorenzoni (2016), Neves, Alves e Gonzalez (2013), Sandroni (2008), dentre outros.

Palavras-chave: Educação. Hospitalar. Aluno. Docente. Aprendizagem.

ABSTRACT: This article focuses on a bibliographical research that makes an in-depth analysis of teaching activities within hospital institutions. A work aimed at pedagogical assistance to students who are in hospital and, therefore, are unable to go to school. The production addresses aspects of the historical context, in which important points are raised that form a timeline of hospital education in Brazil. Added to this, it also brings the legal frameworks that frame hospital education as a modality belonging to special education, a fact that guarantees hospitalized students the full right to education. In addition to these points, the article proposes suggestions for pedagogical practice within hospital spaces, diagnosing situations that allow effective teaching performance and meaningful student learning. Still, aspects of gamification in these spaces are addressed as a way of building cognitive knowledge in hospitalized students. The production had the contribution of Machado and Campos (2013), Berdel (2011), Diesel, Baldez and Martins (2017), Lorenzoni (2016), Neves, Alves and Gonzalez (2013), Sandroni (2008), among others.

Keywords: Education. Hospital. Student. Teacher. Learning.

${ }^{1}$ Graduado em Letras e Direito. E-mail: tocarlos22@gmail.com.

${ }^{2}$ Graduado em Pedagogia e Administração, especialista em psicopedagogia clínica e institucional. E-mail: edilsonraniere@gmail.com.

3 Graduada em Pedagogia, especialista em Psicopedagogia. Email: moraesgerunia@gmail.com. 


\section{INTRODUÇÃO}

A realidade da educação brasileira tem sido, ao longo dos séculos, marcada por um contexto de lutas, e isso reflete em cada modalidade de ensino, principalmente na educação hospitalar. Esta que é caracterizada como uma estratégia que permite aos estudantes hospitalizados dar continuidade à escolaridade mesmo em condições de internação. Apesar de essencial dentro do contexto social, principalmente como garantia do direito à educação a estudantes impossibilitados de frequentar a escola regular, ainda é bastante tímida sua oferta nacional.

Diante disso, o principal objetivo deste trabalho é mostrar a importância e o impacto que a educação hospitalar pode proporcionar a estudantes em situação de internação e, para isso, aspectos históricos são discutidos no intuito de se construir uma visão sistêmica desta modalidade de educação especial, assim como são discutidos os dispositivos legais como a Constituição Federal de 1988 e a LDB (Lei de Diretrizes e Bases da Educação Nacional9.394/96), que garantem este tipo de ensino, o papel e as metodologias adotadas pelo educador neste contexto e a relação deste com o público-alvo da educação hospitalar.

Este estudo é importante porque permite conhecer como acontece a educação dentro dos hospitais, além de diagnosticar que é preciso muito mais do que apenas conhecimentos epistemológicos para a oferta desse tipo de educação, pois como afirmam Machado e Campos (2013), o papel do professor, nesta situação, é de produzir uma ação emancipadora, fato que deixa claro que a relação professor-aluno e vice-versa deve ser bastante profunda e complexa.

\section{DESENVOLVIMENTO}

\section{Desenvolvimento histórico da classe hospitalar no Brasil}

A educação brasileira sempre avançou em um processo lento, em que as principais conquistas normalmente estiveram atreladas ao contexto de lutas. Desde o descobrimento em I50o d.C. que a educação nacional tenta se estabilizar, permitindo qualidade e igualdade de ensino para todos os estudantes.

Com as classes hospitalares a história não foi diferente, pois muito mais recente que a história da educação geral brasileira, a educação hospitalar vem de um surgimento não muito distante e ainda se mostra bastante tímida nos dias atuais. 
A classe hospitalar surge, então, como uma modalidade de atendimento prestado a crianças e adolescentes internados em hospitais e parte do reconhecimento de que esses jovens pacientes, uma vez afastados da rotina acadêmica e privados da convivência em comunidade, vivem sob risco de fracasso escolar e de possíveis transtornos ao desenvolvimento (BARROS, 2007, p. 259)

No início do século XX, segundo Machado e Campos (2013), é possível perceber pequenas manifestações de classes direcionadas a estudantes em situação de internação como, por exemplo, o Pavilhão-escola Bourneville, localizado no Hospício Nacional de Alienados do Rio de Janeiro, que tinha como intuito oferecer a escolarização às crianças internadas. Outras pequenas manifestações podem ser percebidas durante a década de 30 e 40, quando, através da educação especial, surgem classes especiais dentro dos hospitais.

A trajetória permeada desde os anos 50 quando surgiu a primeira classe hospitalar no Hospital Municipal Jesus é desenvolvida de forma morosa. Inicialmente as aulas eram ministradas individualmente, só anos mais tarde, com a criação do setor de Assistência Educacional Hospitalar, que impôs a criação de salas de aula dentro do Hospital Jesus, é que se pôde ter um ambiente específico para ministrar as aulas dentro do próprio hospital.

Anos mais tarde, com a extinção do setor de assistência e a criação do setor de ensino especial e supletivo é que as classes hospitalares tiveram sua primeira menção na legislação educacional, esta referenciada pela LDB de 1969 em seu art. 83, parágrafo 5ํ․

Para Sandroni (2008), nota-se que os hospitais sempre estiveram e ainda estão preocupados em cuidar da saúde da população em seus aspectos físicos e biológicos, porém deixam de lado os fatores psicológicos que são essenciais para a recuperação da saúde e do bem-estar do indivíduo. Certamente a educação hospitalar faz parte dessa esfera psicológica.

Em contrapartida, a história do hospital Jesus, citada acima, é marcante dentro da trajetória da educação hospitalar no Brasil, pois sofreu diversas modificações no tempo e permanece até hoje, realizando este trabalho em espaço próprio, anexo ao hospital. Portanto, toda essa persistência fez com que surgissem vários instrumentos legais que garantem a educação hospitalar, como a Constituição de 1988, a Declaração dos Direitos da Criança e do Adolescente hospitalizado (I995), a Política Nacional de Educação Especial (1994), a lei de diretrizes e bases (9.394/96) e a regulamentação dada pelo MEC em 2002 sobre classes hospitalares e domiciliares. 
Porém, mesmo diante de tantos marcos legais, ainda é bastante tímida a oferta de educação hospitalar no país, levando em conta que há estados como Pernambuco que não são registrados casos desse tipo de atendimento, na pesquisa realizada em 2oII, de acordo com Machado e Campos (2013).

\section{Classe hospitalar e educação inclusiva}

No decorrer de todo o percurso da história, como citado anteriormente, a educação hospitalar teve seu nascimento baseado na educação especial. Diversos dispositivos legais garantem esse direito como a Constituição da República (1988) que traz em seu art. 205 o direito à educação como uma prerrogativa estendida a todos, sendo dever do estado e da família promover esta educação, nos seus mais diversos níveis.

Ainda, O Estatuto da Criança e do Adolescente, segundo Sandroni (2008), traz a proteção dos direitos e garantias da educação para crianças e adolescentes em situação de hospitalização. Numa mesma ideia a LDB (lei de diretrizes e bases da educação nacional), revela no seu artigo 58 a seguinte redação.

Entende-se por educação especial, para os efeitos desta lei, a modalidade de educação escolar oferecida preferencialmente na rede regular de ensino para educandos com deficiência, transtornos globais do desenvolvimento e altas habilidades ou superdotação. (BRASIL, 1996, p. 39)

No parágrafo $2^{\circ}$ do mesmo artigo é garantido que esse ensino especial poderá se dar em outros ambientes, caso não seja possível a integração do estudante na classe regular.

Diante dos marcos legais, é possível perceber que a educação hospitalar entra no rol da educação especial ofertada em um espaço fora do ambiente escolar regular. Nesta perspectiva, a educação hospitalar sempre esteve atrelada à educação especial e as políticas públicas, assim como os dispositivos legais proporcionados à educação especial se estendem também à educação hospitalar, pois esta é entendida como uma forma especial de se garantir a educação.

Porém, apenas a garantia jurídica é insuficiente para que a educação hospitalar tenha êxito no seu objetivo. Para que, de fato, esta modalidade de educação especial possa demonstrar resultados, é preciso que se tenham políticas específicas direcionadas a esse tipo 
de ensino, para que a criança ou o adolescente internado não seja prejudicado nos seus aspectos cognitivos.

A escola hospitalar tem como objetivo possibilitar à criança e ao adolescente hospitalizado a continuação de suas atividades educativas mesmo estando doente, estabelecendo um elo entre a escola de origem e o hospital. $O$ afastamento da criança de sua família, da escola e dos amigos acaba afetando sua autoestima, criança ansiedade, medo, desânimo, depressão e tornando lenta sua recuperação [...] (MACHADO E CAMPOS, 2013, p. 4)

Conforme abordado pelo autor acima, a educação hospitalar tem como principal intuito fazer com que aqueles estudantes que ficam impossibilitados de ir à escola por conta de tratamento constante de saúde possam receber educação dentro do próprio ambiente hospitalar, dessa forma, numa perspectiva inclusiva, é possível evitar o atraso escolar desse aluno que está afastado da escola. Neste contexto, a classe hospitalar evita o comprometimento no desenvolvimento cognitivo do estudante hospitalizado e uma possível evasão, o que reafirma o pensamento de Vasconcelos (2015) sobre classes hospitalares.

Porém, o propósito maior da escolarização hospitalar não está centrado apenas no atraso de ano/série do aluno, mas concentra-se num propósito muito maior. A classe hospitalar permite que a criança ou adolescente fuja por algum tempo do ambiente agressivo em que se encontra, proporcionando ao estudante um retorno à vida cotidiana vivida antes da internação, e isso ajuda significativamente nos fatores psicológicos, principalmente na autoestima, que é um aspecto crucial dentro de um tratamento médico-hospitalar.

Portanto, como afirmam Ortiz e Freitas (200I), é necessário dar à criança a possibilidade de experienciar a hospitalização com maior aceitabilidade, dando a esta hospitalização um caráter mais humano. Este fator é claramente visível quando a escolarização tem espaço dentro do hospital.

Todo esse engajamento proporciona uma política que garante ao estudante em situação de internação o exercício do seu direito à escolarização, garantido na mais extensa legislação nacional, desse modo, a inclusão deste indivíduo se torna mais perceptível, principalmente quando este tipo de escolarização é feita de maneira humanizada. Essa humanização foi garantida, segundo Sandroni (2008), pelo Programa Nacional de Humanização no Atendimento Hospitalar (PNHAH), divulgada pelo Ministério da saúde em 2002. Este programa traz a reflexão para o contexto hospitalar, em que, muitas vezes, 
apenas os aspectos físicos e biológicos são tratados, esquecendo-se dos fatores humanos e psicológicos. Diante disso, o documento procura garantir essa humanização dentro dos hospitais para o tratamento com os pacientes. A escolarização hospitalar é uma forma de contribuir com essa política, pois traz, para a criança e o adolescente em situação de internação, novas perspectivas e objetivos, que perpassam o ambiente em que se encontram.

\section{Formação, prática e metodologias do docente no ambiente hospitalar}

A realidade da criança ou do adolescente que se encontra hospitalizado é uma situação bastante desestimulante, tanto por fatores físicos ou de fragilidade da saúde física, como por seus aspectos emocionais e psicológicos. Diante disso, como o professor da classe hospitalar pode despertar no paciente o desejo de estudar? Quais metodologias de ensino deve adotar?Por quais princípios e objetivos deve se orientar? Como trazer novas perspectivas para esta criança ou adolescente?

Todos esses questionamentos têm a ver com a formação pedagógica a qual o educador possui. Existem muitos fatores inerentes à formação docente que são fundamentais para atuação na escolarização hospitalar.

[...] Os processos de ensino esperados no cotidiano hospitalar não são os mesmos que aqueles realizados numa escola regular. As condições estão fora dos modos de trabalho educativo da escola, onde normalmente a saúde é um requisito, onde a palavra não é necessariamente uma prioridade e onde o silêncio, muitas vezes, é equivalente à atenção. (VASCONCELOS, 2015, p. 30)

Pelo exposto acima, é nítido que o processo de ensino-aprendizagem hospitalar tem suas particularidades que devem ser consideradas pelo professor, porém, o docente, mais do que em qualquer outra modalidade de ensino, precisa trabalhar com o aluno baseado pela afetividade, isso não se caracteriza como um esforço para o professor, uma vez que esse é um requisito que deve estar inerente à prática, independentemente de qualquer exigência neste sentido. A partir do instante em que o estudante hospitalizado se sente seguro diante do educador, as expectativas desse paciente aumentam, auxiliando até na sua perspectiva de alcançar a cura. Neste sentido, a preparação para uma afetividade e para saber lidar com as diversas enfermidades deve ser algo inerente à formação do professor, este deve, principalmente, não se ater à doença, mas sim ao indivíduo, como ser humano em desenvolvimento. 
Complementando o pensamento acima, Machado e Campos (2013) trazem que a relação de afetividade entre professor e aluno hospitalizado possibilita a continuidade da escolarização, além de permitir o respeito ao estudante em suas dificuldades e potencialidades.

Muitos são os aspectos metodológicos que o educador, fazendo uso de sua formação docente, pode usar na interação com seu aluno hospitalizado. $O$ aspecto lúdico deve fazer parte desse contexto, pois é de fundamental importância que instrumentos como os jogos sejam utilizados na perspectiva de um desenvolvimento progressivo prazeroso, mesmo dentro do ambiente em que o aprendiz se encontra, pois para Barros (2007) essa intervenção lúdica reforça a expectativa de retorno à vida normal.

A realidade hospitalar exige que o educador não pense apenas naquilo que quer construir com a criança, mas leve em consideração que estará em um ambiente com mais dificuldades de realizar atividades que o ambiente da escola. Porém, isso não deve ser empecilho para execução de atividades, pelo contrário, nesta situação, o educador precisa buscar métodos e estratégias que se adaptem ao contexto, considerando sempre a condição de saúde em que se encontra o estudante.

O campo pedagógico se insinua no universo hospitalar, acenando para um modo singular de compreensão dos sofrimentos das crianças hospitalizadas e tendo como princípio a promoção da saúde. Assim, a disponibilidade de atividades escolares, e até mesmo lúdicas, consagra-se como uma das variáveis que influem na resposta à hospitalização. (ORTIZ E FREITAS, 2001, p. 72)

O estímulo à leitura é outro fator que pode ser usado como metodologia dentro do espaço escolar, como cita o professor Cláudio César Teixeira do setor de educação e cultura do Hospital Pequeno Príncipe em Curitiba-PR. Este, em suas declarações, relata que a leitura é um fator primordial na educação dos estudantes em situação de internação.

Outros recursos como o uso da música, da fotografia, da pintura e da arte em geral são atividades que proporcionam não só o aprendizado cognitivo, mais trazem para as crianças o sentimento de voltar a sua vida antes da internação. Segundo Neves, Alves e Gonzalez (2016) o atendimento hospitalar permite ao paciente dar continuidade aos seus estudos numa situação de internação de médio ou longo prazo e, para isso, é preciso recorrer a diferentes estratégias didáticas que reforçam a práxis educativa: livros, histórias em quadrinhos, brinquedos, músicas, vídeos, jogos digitais e etc. 
O educador deve ter sempre consciência que o estudante hospitalizado é muito mais do que a enfermidade que apresenta, é um ser humano que necessita receber incentivo de caráter recreativo, educativo e ocupacional, assim como qualquer outro educando, para que possa ter não só um direito garantido, mais uma percepção de futuro.

\section{Relação professor-aluno no contexto hospitalar}

Os fatores intrínsecos à doença são cruciais para o entendimento do aluno como sujeito. É fato que o sofrimento e a infelicidade são bastante perceptíveis, a criança se sente muito mais fragilizada distante do seu contexto familiar e social e isso impacta bastante na sua estrutura emocional, o que dificulta ainda mais sua recuperação. Estes fatores fragilizam bastante a estrutura psicológica do educando hospitalizado, o que compromete sua autoestima e, em muitos casos, vem à tona a depressão.

Para Ortiz e Freitas (200I) é necessário mudar esse cenário acima, ressignificando a função do hospital como espaço onde a vida acontece. Essa ressignificação é construída na relação professor e aluno.

Diante da realidade, como citado anteriormente, a afetividade e a relação de proximidade entre professor e aluno é primordial na recuperação da autoestima do estudante. Neste contexto, o processo de escolarização e a relação estabelecida entre os sujeitos proporcionam não só a aprendizagem da criança, mas também maiores perspectivas na superação de desafios e melhoras na saúde física.

Um aluno que se encontra enfermo e em situação de internação, e que, além disso, se encontra bastante introvertido, calado e deprimido, é possível notar um quadro sério de baixa autoestima e de falta de perspectiva de recuperação da saúde. Nesta situação, o professor deve fazer um trabalho que envolve afetividade, resgatando a autoestima e as perspectivas futuras da criança. Certamente, segundo Machado e Campos (2013), devido ao afastamento do seu ambiente familiar e social, a criança possui medo, ansiedade, desânimo e depressão, e isso prejudica consideravelmente no seu processo de recuperação. Esses aspectos devem ser superados à medida que o professor faz uma escuta pedagógica para ter noção do contexto em que o estudante se encontra e, a partir disso, monta estratégias que não só garantam ao aluno os conhecimentos epistemológicos, mas, principalmente, saberes 
baseados no seu interesse e também na sua realidade e que permitam a ele o resgate da sua confiança e da sua autoestima.

\section{Uso da gamificação na educação hospitalar}

Diante das discussões apresentadas anteriormente sobre a grande importância da oferta da educação hospitalar, faz-se necessário destacar que o trabalho docente dentro dos hospitais precisa ser amparado por metodologias atuais e não pela mera codificação e decodificação de letras e números, que embasam a educação tradicional. Esta que ainda está presente em muitos espaços educativos públicos e privados da atualidade.

No sentido de ofertar uma educação de qualidade dentro dos hospitais, uma estratégia didática que vem ganhando destaque é o uso das metodologias ativas. Estas que são entendidas, segundo Berbel (2011), como formas de desenvolver o processo de aprender usando fatos e experiências reais ou simulados, na perspectiva de solucionar situações da prática social dos mais diferenciados contextos.

Diesel, Baldez e Martins (2017) destacam que:

Assim, em contraposição ao método tradicional, em que os estudantes possuem postura passiva de recepção de teorias, o método ativo propõe o movimento inverso, ou seja, passam a ser compreendidos como sujeitos históricos e, portanto, a assumir um papel ativo na aprendizagem, posto que têm suas experiências, saberes e opiniões valorizadas como ponto de partida para construção do conhecimento. (DIESEL, BALDEZ E MARTINS, 2017, p. 27I).

Consoante o que os autores acima afirmam, as metodologias ativas têm grande impacto dentro do processo de ensino-aprendizagem, uma vez que colocam o estudante como sujeito central na construção do conhecimento. Faz-se, portanto, necessário inserir essa realidade nas classes hospitalares que, mais do que qualquer outra modalidade de ensino, precisa de um ensino propositivo e que coloque o estudante hospitalizado na condição de protagonista. Neste sentido, selecionou-se, nesta produção, a metodologia ativa denominada de gamificação, porém as diversas outras podem ser utilizadas no espaço da educação hospitalar.

Uma das facetas da ludicidade, tão importante no contexto hospitalar, é manifestada no termo gamificação, um conceito relativamente novo para muitos educadores e que não 
deixa de ser, consequentemente, um ato de brincar, aspecto essencial na educação infantil, como preceitua a Base Nacional Comum Curricular (BNCC).

$\mathrm{Na}$ Educação Infantil, as aprendizagens essenciais compreendem tanto comportamentos, habilidades e conhecimentos quanto vivências que promovem aprendizagem e desenvolvimento nos diversos campos de experiências, sempre tomando as interações e a brincadeira como eixos estruturantes. Essas aprendizagens, portanto, constituem-se como objetivos de aprendizagem e desenvolvimento. (BRASIL, 2018, p.40)

Através do excerto da BNCC, é possível verificar que a brincadeira ou ato de brincar é de fundamental importância, sendo referenciado no documento que norteia a educação nacional, que por sua vez, é embasado também pelas considerações do psicólogo bielo-russo Levi Vygotsky, que atribui à brincadeira e aos jogos importante papel no processo de desenvolvimento infantil, algo que não deve se perder numa situação de internação.

Diante do exposto, volta-se à discussão sobre o foco de pesquisa do termo apresentado anteriormente, a gamificação. Termo este que se insere dentro do campo da ludicidade e da brincadeira.

A gamificação, utilizada no contexto educacional hospitalar, pode ser entendida como a utilização de jogos ou recursos de jogos para fins didáticos. Trata-se de uma estratégia lúdica em que a disputa, a premiação e a adrenalina se fazem presentes e são utilizadas para gerar aprendizagem, tudo isso de maneira espontânea e prazerosa.

Segundo Lorenzoni (2016), a gamificação é uma das apostas da educação contemporânea, uma vez que ela funciona para despertar o interesse, aumentar a participação, desenvolver a criatividade, autonomia e, consequentemente, gerar diálogo e resolução de situações problemas.

Aspectos citados acima se tornam cruciais quando se fala da educação de crianças que estão em situação de internação hospitalar, pois, o trabalho com essas crianças exige dos educadores recursos cada vez mais chamativos e que contribuam significativamente no seu processo de desenvolvimento, especialmente por se encontrarem em espaços que, muitas vezes, impossibilitam os alunos de se desenvolverem cognitivamente.

Ainda conceituando o termo gamificação, é possível destacar o pensamento de Fardo (2013), que destaca a gamificação como a capacidade de abstrair os recursos e potencialidades dos games para utilizar em outras atividades que não são relacionadas a games. Corrobora 
com o mesmo pensamento Bussarelo (2016), acrescentando que a intenção é promover a motivação e estimular o comportamento do indivíduo.

Os autores ainda deixam claro que a gamificação é um recurso que explora o nível de envolvimento da criança para, assim, alcançar seu objetivo. Desse modo, trazendo a ideia para o contexto hospitalar, é possível determinar que o educador utiliza a ferramenta no processo de ensino-aprendizagem aproveitando o nível de envolvimento dos educandos hospitalizados, uma vez que este envolvimento é relativamente superior comparado a atividades cotidianas e rotineiras desenvolvidas nas classes hospitalares.

Pensando-se na gamificação como uma prática colaborativa, é importante destacar que este recurso é utilizado de maneira a desenvolver as diversas habilidades nos mais diferentes aspectos. A partir do momento em que o educador que leciona para estudantes enfermos usa esta estratégia, o intuito não é e nem pode ser apenas envolver o estudante na atividade, além desta pretensão, é necessário que o professor agregue às atividades gamificadas objetivos de aprendizagem, no sentido de desenvolver habilidades de maneira integral no aluno, em que este possa, através da gamificação, ter garantidos os direitos de aprendizagem como, por exemplo, conviver, brincar e participar-expressos na BNCC.

Uma característica bastante peculiar dentro deste processo de uso da gamificação, seja dentro seja fora do espaço hospitalar, mas que se destaca claramente dentro deste, principalmente pela intencionalidade do professor, é o fato de despertar no educando aspectos relacionados ao sentimento de colaboração, de ajuda mútua e de compartilhamento, elementos tão essenciais no processo de desenvolvimento infantil.

Segundo Fadel et. al (2014), o compartilhamento e a colaboração são aspectos que se sobressaem à recompensa, construindo, através da gamificação e dos jogos, um bem maior. Outro fator destacado pelos autores é o desafio que está imbuído dentro destas ferramentas.

[...] O desafio é um elemento propulsor para motivar e engajar os jogadores, estabelecendo objetivos que devem ser alcançados a curto, médio e longo prazo, mediante as estratégias que mobilizam funções cognitivas e subjetivas. $\mathrm{O}$ sistema de feedback é fundamental para subsidiar e retroalimentar o processo de engajamento dos jogadores, informando seu percurso para alcançar os objetivos propostos. (FADEL et. al, 2014, p.8o)

Se o desafio é um fator determinante, que impulsiona o sujeito dentro de atividades de gamificação, analisando-se esta atividade dentro do espaço hospitalar fica evidente que a 
contribuição deste recurso está efetivamente relacionada ao nível de envolvimento que a criança tem com a atividade. Uma vez desafiada e motivada a superar desafios ou até mesmo receber algum tipo de prêmio ou recompensa, a criança se envolve de maneira total, sem nenhum tipo de receio ou recusa. Esse é o diferencial da gamificação dentro do espaço hospitalar, pois ela faz um caminho inverso à metodologia tradicional de ensino. Enquanto esta ensina para motivar, naquela acontece uma inversão, ela motiva para ensinar.

Burke (2015) complementa afirmando que as pessoas sentem motivação de várias maneiras diferentes, um dos modos de mantê-las motivadas é através de desafios práticos que possam encorajar as pessoas e mantê-las emocionalmente envolvidas até alcançar o melhor resultado. Neste sentido, a gamificação propõe constantemente diversos desafios, sendo de essencial importância nas classes hospitalares.

Apesar do conceito e da etimologia da palavra ser algo que vem desde os anos 80 do século passado, as atividades que envolvem a gamificação ainda são bastante tímidas nas classes hospitalares.

Como exemplo de atividade com a gamificação, a partir dos níveis de leitura e escrita- pré-silábico, silábico, silábico-alfabético e alfabético- o professor pode propor desafios em que o estudante se sinta motivado a mudar de nível e, em troca, ser também premiado a cada mês.

A mudança de nível guardada apenas para o professor é algo muito abstrato e que não faz sentido para o estudante. A partir do momento em que o aluno se envolve, como forma de desafio, ele reconhece a sua condição como parte do processo, ao mesmo tempo em que se sente desafiado a mudar de nível. Este é um processo que pode envolver, inclusive, as famílias dos estudantes hospitalizados, que devem ser chamadas a participar do processo, formando assim uma "força-tarefa".

Em conjunto com a família, a escola exerce um papel importantíssimo na formação da identidade pessoal e social da criança. Em especial, para a criança cronicamente enferma, a manutenção de atividades que resgatem a rotina de sua vida anterior à doença, como as escolares, representa possibilidades concretas de que ela cultive acesa a esperança de sobreviver, por meio da construção do seu próprio futuro. (HOLANDA E COLLET, 2012, p. 37)

Através do exemplo apresentado, é possível verificar a abrangência e a significação que a gamificação traz para o processo de ensino-aprendizagem, especialmente para os 
estudantes em condições de internação. Um aspecto que pode parecer tão subjetivo e particular do docente, transforma-se num instituto compartilhado com estudantes e familiares.

Outra faceta da gamificação é a utilização desta ferramenta de modo virtual, através das mídias digitais, amplamente imbuídas no contexto social contemporâneo. Diante deste cenário, é possível utilizar-se desta ferramenta, através de seus recursos digitais que são largamente abrangentes. Para Fadel et. al (2014), a gamificação em ambiente virtual pode contribuir como reforço e feedback de conhecimentos tratados em sala de aula, assim, reafirma que este recurso aplicado na educação hospitalar pode ser usado de diferentes formas pelo professor, seja de modo de presencial ou online.

O educador, como profissional inovador, pode fazer o uso das diversas ferramentas e, até mesmo, jogos que se encontram disponíveis de modo virtual, para abstrair destas situações geradoras de aprendizagem, aproveitando recursos virtuais e elementos que favoreçam o processo de ensino-aprendizagem. Pode aproveitar o momento atípico vivenciado pelo estudante para propor estratégias virtuais que envolvam a gamificação.

\section{CONSIDERAÇÕES FINAIS}

Diante de toda abordagem exposta sobre a educação hospitalar, é possível ter uma visão mais apurada de como esta funciona e como deve ser proporcionada e qual o público que deve recebê-la. Por ter uma trajetória relativamente recente, foi possível perceber que as classes e o atendimento educacional dentro do ambiente hospitalar ainda são bastante tímidos, levando em consideração que essa demanda é relativamente expressiva.

Através do diagnóstico histórico foi possível verificar o quanto se tem avançado neste tipo de educação, porém, é mínimo o atendimento se levar em consideração que nos dias atuais ainda pouco se discute sobre o assunto. Esses pontos foram abordados através da evolução deste tipo de educação no Brasil no decorrer da história e trouxe, atrelado ao contexto histórico, as inúmeras legislações como a LDB 9.394/96 e o Estatuto da Criança e Adolescente Hospitalizado, ambas as legislações bastante recentes, mas consideradas marcos que garantem o direito primordial à educação. 
$\mathrm{Na}$ perspectiva da educação inclusiva, é possível observar o quanto à educação hospitalar está atrelada à educação especial, sendo interpretada como modalidade desta. Este conhecimento permite uma visão maior deste tipo de educação em que está ligada às capacidades e interesses dos educandos em situação de internação.

A abordagem do uso da gamificação no processo de ensino-aprendizagem de crianças em situação de internação permite observar que as barreiras impostas no ambiente hospitalar tornam-se mínimas diante de tal recurso, pois este coloca o estudante como protagonista de sua própria aprendizagem e pode eliminar as distâncias físicas entre o estudante enfermo e seus colegas de sala, se atrelada às tecnologias digitais.

Por fim, vale destacar, que a atuação do educador produz uma nova perspectiva no educando hospitalizado, melhorando sua autoestima e, em muitos casos, seu quadro clínico. Isso reafirma que o trabalho do educador no ambiente hospitalar, feito com metodologias apropriadas e, principalmente, fazendo uso da afetividade, gera resultados além dos esperados.

\section{REFERÊNCIAS}

BARROS, Alexandra Santana Soares. Contribuições da educação profissional em saúde à formação para o trabalho em classes hospitalares. Cad. Cedes, Campinas, vol. 27, n. 73, p. 257-278, set./dez. 2007. Disponível em 〈https://www.scielo.br/j/ccedes/a/9ypnzYpSWNt366Gw5GMHmTp/?format=pdf\&lan $\mathrm{g}=\mathrm{pt}>$ Acesso em 03 de dez. 2021.

BERDEL, Neusi Aparecida Navas. As metodologias ativas e a promoção da autonomia de estudantes. Semina: Ciências Sociais e Humanas, Londrina, v. 32, n. I, p. 25-40, jan./jun. 20II. Disponível em <https://www.uel.br/revistas/uel/ index.php/seminasoc/article/view/ro326/10999> Acesso em 30 de nov. 2021.

BRASIL. Constituição da República Federativa do Brasil. Brasília: Senado Federal, Coordenação de edições técnicas, I988.II9 p.

BRASIL. LDB : Lei de diretrizes e bases da educação nacional. Brasília: Senado Federal, Coordenação de Edições Técnicas, 1996.58 p.

BRASIL. Ministério da educação. Secretaria executiva. Secretaria de educação básica. Conselho nacional de Educação. Base nacional comum curricular (BNCC). Brasília, DF: MEC; secretaria executiva; SEB/CNE, 2018. Disponível em < http://portal.mec.gov.br/index.php?option=com_docman\&view=download \&alias=796or- 
anexo-texto-bncc-reexportado-pdf-2\&category_slug=dezembro-2017-pdf\&Itemid=30192> Acesso em: I8 jul. 2020. > Acesso em I4 de nov. 2021.

BURKE, Brian. Gamificar: como a gamificação motiva as pessoas a fazerem coisas extraordinárias. São Paulo: DVS Editora, 2015.

BUSSARELO, Raul Inácio. Gamification: princípios e estratégias. São Paulo: Pimenta Cultural, 2016. I26p.

DIESEL,Aline; BALDEZ, Alda Leila Santos; MARTINS, Silvana Neumann. Os princípios das metodologias ativas de ensino: uma abordagem teórica. Revista Thema, 2017, v.I4, n- ${ }^{\circ}$. Disponível em <https://periodicos.ifsul.edu.br/index.php/ thema/article/view/404/295> Acesso em 30 de dez. 202I.

FADEL et. al (org). Gamificação na educação. São Paulo: Pimenta Cultural, 2014. 30op.

FARDO, Marcelo Luís. A gamificação aplicada em ambientes de aprendizagem. Renote, V. II № I, julho, 2013. Disponível em < https://www.seer.ufrgs.br/renote/ article/view/41629/26409> Acesso em or de dez. 202I

HOLANDA, Eliane Rolim; COLLET, Neusa. Escolarização da criança hospitalizada sob a ótica da família. Texto Contexto Enferm, Florianópolis, 2012 Jan-Mar; 2I(I): 34-42. Disponível em <https://www.scielo.br/j/tce/a/9y6KybZ 5 cgjbBY $5 g S_{3} F D D d n /$ ?format=pdf\&lang=pt $>$ Acesso em 03 de dez. 2021.

LORENZONI, Marcela. Gamificação: o que é e como pode transformar a aprendizagem. 20I6. Disponível em < https://www.geekie.com.br/blog/gamificacao/

$>$ Acesso em 02 de dez. de 202I.

MACHADO, Jucilene; CAMPOS, Jurema. Relação Professor - Aluno: Um diferencial na Classe Hospitalar. XI Congresso Nacional de Educação. EDUCERE. 2013. Curitiba.

Disponível em < http://educere.bruc.com.br/arquivo/pdf2o13/ I0499_7066.pdf > Acesso em I3 de nov. 2021.

NEVES, Isa; ALVES, Lynn; GONZALEZ, Carina. Jogos digitais nas classes hospitalares: desbravando novas interfaces Obra digital- ISSN 2014-203, no 10-fevereiro 2016. Disponível em <https://www.readcube.com/articles/ro.25029\%2 Fod.2016.74.10> Acesso em o3 de dez. 2021.

ORTIZ, Leodi Conceição Meireles; FREITAS, Soraia Napoleão. Classe hospitalar: um olhar sobre sua práxis educacional. R. bras. Est. pedag., Brasília, v. 82, n. 200/201/202, p. 7077, jan./dez. 20or. Disponível em <http://rbep.inep.gov.br/

ojs3/index.php/rbep/article/1350/ıoview/89> Acesso em o3 de dez. 2021. 
SANDRONI, Giuseppina Antonia. Classe Hospitalar: Um recurso a mais para a inclusão educacional de crianças e jovens. Cadernos da Pedagogia - Ano 2, Vol.2, No.3 jan./jul. 2008. Disponível em: 〈http://www.cadernosdapedagogia.ufscar.br/ index.php/cp/article/view/50/43> Acesso em I3 de nov. 202I

VASCONCELOS, Sandra Maia Farias. Histórias de formação de professores para a Classe Hospitalar. Revista Educação Especial. Vol. 28. N. 51. 2015. Disponível < https://periodicos.ufsm.br/educacaoespecial/article/view/9ir8> Acesso em or de dez. 2021 . 